\title{
Moda pelo avesso: compartillhamento de produção acadêmica para transformação de realidades
}

Fashion inside out: sharing academic production to transform realities 


\section{[NAYARA CHAVES FERREIRA PERPÉTUO]}

Professora no Instituto Federal do Maranhão (IFMA).

\section{E-mail: nayarachaves@ifma.edu.br}

[resumo] 0 objetivo deste artigo é demonstrar como é possível articular a teoria e a prática no âmbito do ensino de Moda, extrapolando os muros das instituições de educação. Para isso, aborda o planejamento, a execução e os resultados do projeto de extensão intitulado Moda pelo avesso que foi idealizado para apresentar os resultados da pesquisa de mestrado de uma docente da rede federal de ensino à comunidade da cidade de Zé Doca, no Maranhão. Ele culmina trazendo à tona o retorno social da escola que incentiva e divulga a pesquisa, além de promover reflexões importantes na contemporaneidade envolvendo práticas sustentáveis e questionando o papel dos agentes implicados nas relações de consumo - designers e consumidores.

\section{[palavras-chave]}

\section{design de moda; pós-graduação em} Design; qualificação docente; ensino.

[abstract] The objective of this article is to demonstrate how it is possible to articulate theory and practice in the scope of fashion education, extrapolating educational institutions walls. For this, addresses the planning, execution and results of the Extension Project entitled Fashion Inside Out, which was idealised to present the results of the master's degree research of a lecturer of the Federal Education system to the Zé Doca community (Maranhão). It culminates bringing out the social return of the school that encourages and disseminates the research, in addition to promote important reflections in the contemporaneity involving sustainable practices and questioning the role of agents involved in consumer relations - designers and consumers.

[keywords] fashion design; design post-graduation; teaching qualification; education. 


\section{O contexto, o projeto e os envolvidos}

No Instituto Federal de Educação, Ciência e Tecnologia do Maranhão (IFMA), os servidores, ao serem afastados de suas atividades regulares para participar de programas de pós-graduação stricto sensu no país e no exterior, devem cumprir com as obrigações referentes à Resolução 84/IFMA, de 5/10/2011, entre elas, 0 artigo VIII que assinala que o pós-graduado deve, "em um prazo máximo de 6 (seis) meses, após o retorno ao Instituto Federal do Maranhão, apresentar o trabalho desenvolvido, bem como seus resultados à comunidade".

No sentido de cumprir com tal resolução, a servidora afastada para realizar o mestrado e autora deste artigo desenvolveu o projeto de extensão Moda pelo avesso. 0 objetivo era compartilhar os resultados de sua pesquisa de mestrado intitulada No cabide: a percepção das digital influencers sobre a estratégia de design para otimização de produtos (PERPÉTUO, 2017), desenvolvida no programa de pós-graduação em Design na Universidade Federal do Maranhão (UFMA).

Neste artigo, demonstra-se como um projeto de extensão configura-se em uma possibilidade viável para articular a teoria e a prática no âmbito do ensino de Moda, extrapolando os muros das instituições de educação.

Para isso, é necessário primeiramente abordar a pesquisa de mestrado apresentada por meio desse projeto. Ela evidencia, em seus resultados, algumas ações da estratégia do design para otimizar a vida de produtos de moda e também identifica como elas são percebidas pelas digital influencersa partir de uma noção de sustentabilidade que não é totalmente considerada durante o uso, devido à valorização de aspectos simbólicos e culturais.

0 projeto, além de atender o que exige a resolução já citada, ganhou uma conotação maior. Mais do que compartilhar informações, desejava-se fazer esse compartilhamento de maneira interessante para a comunidade, dando-lhe retorno prático.

0 formato de apresentação dos resultados não é imposto institucionalmente e cabe a cada servidor definir como o fará. Além do estímulo à capacitação, são oportunizados aos servidores diversos editais de incentivo tanto à pesquisa quanto à extensão. Pensando no alcance das ações de extensão, cuja abrangência extrapola a comunidade escolar, escolheu-se apresentar os resultados da pesquisa sobre o formato aqui relatado. 
A localidade onde se dá a realização do projeto é a cidade de Zé Doca, no Maranhão, com 50.173 habitantes, segundo os dados do IBGE (2010). 0 IFMA atua como agente formador nesse municipio desde 2007 e juntamente com a prefeitura da cidade identificou que a população da região é formada, na sua maioria, por familias carentes, apesar do potencial do município. 0 campus tende a adequar as suas ofertas de ensino, pesquisa e extensão às necessidades locais e, assim, em 2011, iniciou a implantação do eixo Produção Cultural e Design, integrando as áreas de produção de vestuário e moda. Tal implantação provocou grande expectativa na cidade, que acolheu todas as iniciativas institucionais envolvendo a área, tais como cursos de curta duração, oficinas, minicursos etc.

Socializar os resultados da pesquisa, mais do que uma contrapartida do servidor à comunidade, é uma excelente oportunidade para tornar a ciência acessivel, sobretudo quando os trabalhos acadêmicos estão voltados para 0 estudo de realidades que são próximas a nós e contribuem para o desenvolvimento local.

Assim, buscou-se um formato capaz de aliar a produção acadêmica e o conhecimento científico com a vida das pessoas, contribuindo efetivamente para a transformação de realidades e problematizando o papel do consumidor como cidadão ativo na solução dos problemas que nos distanciam da sustentabilidade. Desse modo, o formato suscitou reflexões importantes sobre as práticas sustentáveis no uso das roupas e questionou o papel dos agentes envolvidos nas relações de consumo - designers e consumidores.

\section{0 que compartilhar?}

Sabemos que uma dissertação de mestrado consiste em uma pesquisa ampla, cujo volume de informações é razoável e, muitas vezes, sua linguagem pouco acessivel ou interessante para grande parte da população. Logo, fazer uma síntese da pesquisa foi necessário para pensar um processo de socialização. Este item, portanto, dedica-se a apresentar tal sintese, já que esta também é oportuna para as discussões propostas neste artigo.

A pesquisa realizada partiu do pressuposto de que o Design, como área de conhecimento, possui ferramentas capazes de contribuir para 0 desenvolvimento de práticas e estilos de vida sustentáveis por meio de propostas que comparam, de modo avaliativo, as implicações ambientais e as diferentes soluções técnicas, econômicas e socialmente aceitáveis.

No campo da moda, sem dúvida, a sustentabilidade é uma das maiores críticas já enfrentadas porque a desafia amplamente, desde o uso de materiais e processamentos no desenvolvimento de artefatos até os modelos econômicos e sistemas de crenças e valores.

Os produtos de moda estão longe de ser uma criação artística que escapa à razão ou a mera expressão da futilidade alheia. Eles são uma construção racionalizada e, por isso, os problemas por eles gerados devem ser administrados 
também racionalmente, projetando-se possibilidades para novos cenários de estilos de vida, produção e consumo.

Na concepção do produto de moda, a adoção de práticas sustentáveis tem se tornado possivel e muito é feito para inovar e melhorar as credenciais de sustentabilidade nos itens com o uso de algumas estratégias, entre elas: a minimização de recursos, a escolha de recursos e processos de baixo impacto ambiental, a otimização da vida de produtos, a extensão da vida dos materiais e para facilitar a desmontagem.

Entre as diversas atuações dos designers para alterar a dinâmica dos produtos, está a estratégia para otimizar a vida de produtos. Ela é proposta pelos autores Manzini e Vezzoli (2008) e apontada no banco de dados Eco.cathedra, desenvolvido pelo Politécnico de Milão (Polimi), como aquela que contribui significativamente para o adiamento do descarte.

Em uma primeira fase da pesquisa foi possivel identificar oito ações de design propostas pelo Eco.cathedra, embora não tenham sido pensadas para produtos tão efêmeros como os de moda. As ações identificadas foram: projetar a duração adequada (1), projetar a fidelidade (2), facilitar a atualização e a adaptabilidade (3), facilitar a manutenção (4), facilitar o reúso (5), facilitar o reparo (6), facilitar a refabricação (7) e intensificar o uso (8).

Tais ações são aplicáveis aos artefatos com repercussão associada à fase de uso, logo, envolvendo diretamente o consumidor. Coube, portanto, em uma segunda fase, identificar como, na prática, elas eram percebidas pelos consumidores, evidenciando as lacunas possiveis entre os estágios de produção e 0 consumo dos produtos de moda.

As ações de design para otimizar a vida dos produtos resultam em um efeito em cadeia rumo a um decrescimento gradativo que se torna possivel graças ao prolongamento da vida útil do vestuário de moda. É provocado um aumento da fase de uso que, por sua vez, adia o descarte e a produção de novos produtos. Contudo, ainda perduram como grandes desafios o equilibrio dos sistemas de produção, modelos de negócio que promovem e vendem as peças e o comportamento de quem as compra.

Uma percepção comum na indústria da moda, segundo Salcedo (2014), é de que uma vez nas mãos do consumidor, o produto deixa de ser uma responsabilidade do designer. Inúmeros problemas originam-se desse distanciamento. Ao transpor a linearidade para uma relação cíclica, como são propostos os pensamentos sustentáveis, os paradigmas firmados até então são repensados.

A moda enquanto fenômeno sociológico existe pela coletividade, sendo essencial que haja consenso e individuos que acreditem, concordem e consumam essa ou aquela ideia. Para que isso ocorra, especialmente no âmbito dos produtos, faz-se necessária também uma indústria de produção de bens de consumo. Logo, materialidade e imaterialidade se fundem e também apontam 
suas duas facetas comumente imbricadas, sendo uma de mudança social e outra de indústria (GODART, 2010), principalmente de vestuário.

Por causa da regularidade das mudanças propostas nos lançamentos das coleções de roupas, normalmente de forma sazonal (primavera/verão e outono/inverno) e não cumulativas, é instituído o ciclo da moda distribuído nas fases lançamento, consenso, consumo, massificação e desgaste.

A manutenção do ciclo da moda é amplamente fomentada pelos meios de comunicação. Na atualidade, as mídias digitais ganharam papel de destaque e são meios eficazes na difusão de informações, permitindo a conexão entre produtores e consumidores e uma modelagem cultural da moda, legitimando-a. Pois é por meio da mídia que o grande público tem acesso às coleções, ou seja, de maneira indireta. "A mídia constitui uma verdadeira interface, ou um filtro entre os criadores de moda e os consumidores finais que compram as roupas" (GODART, 2010, p. 124).

Bauman (2008), em Sociedade para o consumo, diz que os sujeitos, quando equipados de confessionários eletrônicos portáteis, são apenas aprendizes treinando e treinados na arte de viver em uma sociedade confessional, aquela que não separa mais o público do privado, transformando a exposição em um dever.

Nesse contexto, qualquer pessoa com acesso à internet pode produzir e lançar informações na rede por meio das mídias sociais, como os blogs. Estes são conceituados como páginas pessoais em formato de diário, de fácil criação e manuseio, nas quais são postadas publicações em ordem cronológica. Com o tempo, os assuntos das publicações foram se segmentando, fazendo surgir na internet blogs com temáticas específicas, como é o caso dos de moda. Nessa especificidade, o gênero feminino é ator protagonista e suas autoras são conhecidas como blogueiras.

Se antes eram as edições mensais de revistas de moda que disseminavam tendências, hoje a revolução digital faz dos blogs um recurso que atende essa caracteristica em tempo real. De forma comparativa, as revistas possuem linguagem impessoal enquanto nos blogs a subjetividade é o diferencial. Editoriais muito elaborados e distantes da realidade dos consumidores, normalmente, são apresentados por modelos com padrões de beleza pouco acessíveis, enquanto as blogueiras mostram, por meio de sua autoimagem, possibilidades reais. 0 estilo de vida (1); o fato de não serem nem artistas inatingiveis, nem totalmente anônimas (2); e de iniciarem seus blogs sem vínculos comerciais (3) deixam as blogueiras livres para relatar suas experiências com os produtos e fazem com que tenham um grau de pessoalidade maior com o público.

A subjetividade das blogueiras é expressada nas publicações e os leitores começam a acompanhá-las continuamente, principalmente por se identificarem com o estilo de cada uma. Aos poucos, as anônimas vão se caracterizando como formadoras de opiniões ou digital influencers. 
Esses canais, uma vez descobertos pelo mercado, não somente retransmitem informações, mas também promovem uma educação do público para receber os produtos lançados, garantindo-lhe melhores condições para se legitimar como consumidor de moda.

A influência exercida pelas formadoras de opinião não está nelas enquanto pessoas que possuem certa competência no assunto, mas na rede social à qual cada uma delas pertence (ERNER, 2015). Por isso, é no seu cotidiano que se encontram os contatos sociais responsáveis por fazer crescer a passos largos a quantidade de seguidores e mensurar a sua difusão.

Segundo o sociólogo Guillaume Erner (2015), a principal qualidade das blogueiras é servir como nó de informação, logo, colocar em contato indivíduos uns com os outros. Isso é possivel pois elas participam de lançamentos de coleções, inaugurações de lojas, são entrevistadas, frequentam e realizam eventos e mantêm mídias sociais atualizadas constantemente, além de serem a qualquer momento identificadas e abordadas nas ruas.

A atuação das blogueiras já deixou de ocorrer apenas por meio dos blogs e acompanhou as mudanças havidas no ambiente on-line. Elas estão presentes em várias outras mídias sociais na internet, entre elas o YouTube, 0 Twitter, o Instagram e o Snapchat, além de redes sociais como o Facebook. Essas mídias e a rede caracterizam-se pela interação, pela colaboração e pela criação de conteúdo.

Para cada especificidade - vídeo, imagem ou texto - há uma produção de conteúdo que leva em consideração, principalmente, a variação de público. Logo, rotular aquelas que fazem uso desses espaços apenas como blogueiras tornou-se um equívoco reconhecido durante a execução da pesquisa. A nomenclatura digital influencers, embora menos disseminada, é como elas se identificam e, por isso, é a adotada.

Após a compreensão do ciclo da moda, percebe-se, agregadas às suas fases, as digital influencers orientando, por meio de suas vivências e representações, as percepções das pessoas em relação às roupas.

Em blogs e outras mídias sociais, é comum observar o estímulo à valorização das funções simbólicas em detrimento das utilitárias. Dessa forma, 0 descarte de produtos ainda em condições de uso e a obsolescência simbólica e cultural tornam-se cada vez mais intensos, passando a ser naturalizados pelos consumidores.

A dissertação apresentada pelo projeto culminou em identificar se havia, e quão ampla poderia ser, a lacuna entre o projeto desenvolvido a partir da estratégia para otimizar a vida de produtos e a percepção das ações de design pelas digital influencers no uso dos produtos de moda.

Para dar conta deste objetivo foi adotada, inicialmente, uma abordagem etnográfica, ampliada, posteriormente, para a aplicação da cartografia. 
Durante dez meses de trabalho de campo, constituíram-se como sujeitos/ participantes da pesquisa quatro digital influencers.

Foram importantes para essa pesquisa questões que advêm do consumo, como a efemeridade e a permanência dos artefatos, valorizando os seus aspectos simbólicos; a construção da identidade a partir do vestuário; e o papel da pesquisadora que, presente em campo, também é ator que influencia a percepção dos sujeitos de pesquisa, como enfatizado nas abordagens reflexivas da etnografia.

A pesquisa de campo trouxe como resultados a percepção clara de seis das oito ações de design dispostas no Eco.cathedra, sendo elas: projetar a duração adequada (1), projetar a fidelidade (2), facilitar a atualização e adaptabilidade (3), facilitar a manutenção (4), facilitar o reparo (5) e intensificar o uso (8). As ações de facilitar o reúso (6) e facilitar a refabricação (7) não foram percebidas pelo escopo explicitado no banco de dados.

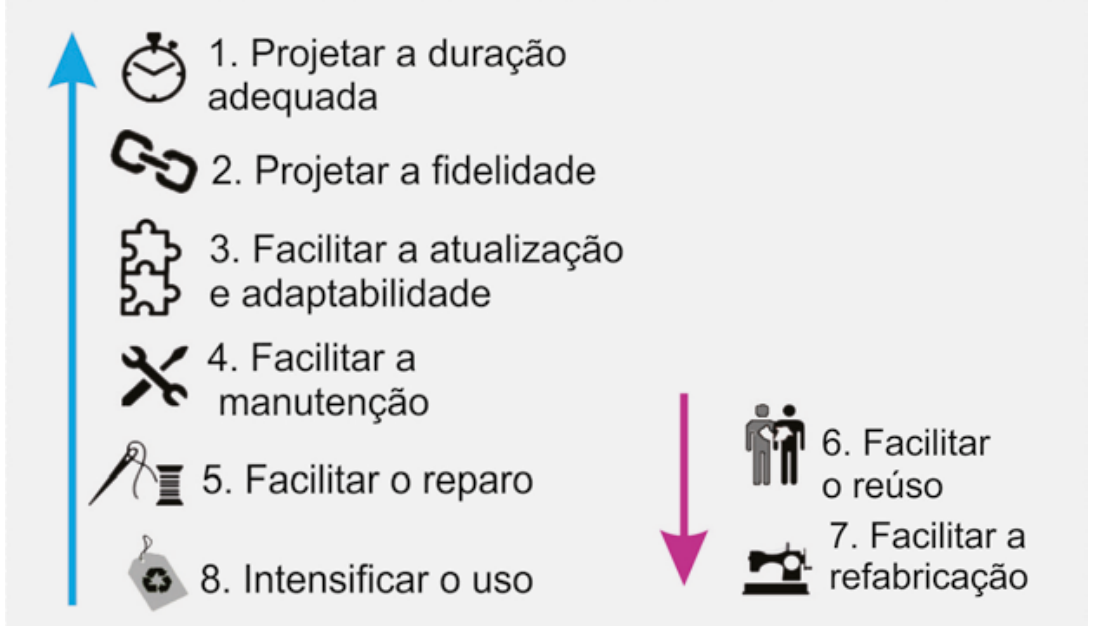

Figura 1 - Ações da estratégia de otimização da vida de produtos percebidas e não percebidas. Fonte: Elaborado pela autora (2017).

A ação de design para projetar a duração adequada (1) em um contexto de produtos de moda está associada às concepções de fast fashion e slow fashion. Estas caracterizam-se principalmente pela velocidade com que o processo de criação, produção, distribuição e venda dos produtos ocorre. Por consequência dessas práticas, a forma de consumo e o descarte também se distinguem em mais rápido ou mais lento. Nesta pesquisa, a primeira concepção é percebida pelas digital influencers devido ao conhecimento e à intimidade que elas têm com o campo da moda, por isso procuram usar as tendências quando estas são adequadas ao estilo pessoal de cada uma. Já a segunda concepção associa-se às relações emocionais que estabelecem com as roupas ora por um direcionamento proposital do designer da marca, ora por uma construção cultural que ocorre entre os sujeitos e os objetos.

Os conceitos de produtos neutros e básicos evidenciados pelas digital influencers no cotidiano fazem com que elas identifiquem as ações de projetar a 
fidelidade (2) e facilitar a atualização e adaptabilidade (3). Elas fazem isso por considerarem os produtos desenvolvidos sob esses conceitos versáteis, logo, possibilitam a composição de looks diversos. Isso também ocorre com aqueles multifuncionais, quando as funções são conhecidas.

As ações de facilitar a manutenção (4) e facilitar o reparo (5) deixam um pouco de lado as questões relativas aos aspectos simbólicos, como a novidade, que causam obsolescência do produto. A primeira volta-se para processos de higienização (lavar, secar e passar a ferro) e armazenamento. Logo, a manutenção adequada está diretamente ligada à durabilidade das peças. Já a segunda volta-se para a troca de aviamentos frágeis, como botões e pedrarias. Esta só é aplicada de fato quando é condicionante ao uso, senão deixa de ser priorizada, causando uma obsolescência tecnológica ao produto.

Por fim, as digital influencers recorrem ao Product Service System (PSS) como uma ação de design que intensifica o uso das peças (8). Exemplos dessa ação voltada para o uso compartilhado de produtos de moda são os aluguéis de roupas. Estes, infelizmente, não são explorados em toda a sua potencialidade e limitam-se a vestidos para ocasiões festivas.

Para além de entender como as estratégias de design estudadas são percebidas, observou-se em campo estratégias aplicadas diretamente pelas digital influencers que não são sinalizadas dentro do escopo do banco de dados Eco.cathedra, mas que poderiam ser incorporadas a ele.

A ação de facilitar o reúso (6) foi identificada pelo compartilhamento direto de roupas. Esta prática bottom-up deve ser percebida como uma oportunidade de negócio, sendo, inclusive, uma demanda latente para projetos de PSS específicos, por exemplo, guarda-roupas coletivos. Foi possivel identificar também que a intensificação do uso do produto (8) ocorre via bazar, brechó e revenda direta entre os consumidores, usando como recurso as mídias sociais. A customização de peças também foi sinalizada em campo como um interesse das digital influencers para prolongar o uso de alguns produtos e podemos enquadrá-la como uma ação de facilitar a refabricação (7).

Assim, as lacunas existentes entre aquilo que é projetado e o uso de produtos de moda estão relacionadas principalmente às ações de design que não são percebidas integralmente pelas digital influencers ou praticadas por elas independentemente de um direcionamento dos designers, tais como: facilitar a manutenção (4) quando as etiquetas são ineficazes, pouco atrativas e de difícil compreensibilidade; facilitar o reparo (5) quando não são considerados os consumidores com pouca habilidade manual; e facilitar o reúso (6) quando não são consideradas as possibilidades Sistema Produto Serviço ou Product Service System (PSS) para customização.

Esta pesquisa estabelece um diálogo com grande parte da população da cidade de Zé Doca já que aborda o consumo. Ao expor os resultados do estudo realizado com as digital influencers, buscou-se estimular outras pessoas a se 
identificar com as práticas de consumo conscientes que elas desenvolvem e a problematizar seus papéis de consumidores/cidadãos.

\section{Por que compartilhar?}

Reflexões sobre o consumo, mais do que em qualquer outro momento, precisam estar na moda. Elas são um primeiro e essencial passo rumo a uma mudança de postura que cada um de nós precisa fazer para existir, respeitando a capacidade de resiliência do planeta.

Segundo Lipovetsky (2007, p. 34), "vivemos em uma sociedade da superabundância de ofertas, da desestabilização da cultura de classes" somadas a um enaltecimento da novidade que, conforme o mesmo autor, areja e rejuvenesce o cotidiano.

Carvalhal (2016), em Moda com propósito, sinaliza que desde os anos 2000, ao forçarmos o tempo, acabamos não dando conta de acompanhá-lo. Fato que comprova isso são as inspirações em décadas anteriores, revisitando e recriando estilos, culminando em cópias e reproduções explícitas. Comprar por comprar, comprar para acumular e comprar para ficar na moda movimenta um processo autodestrutivo, mas vendido como acesso à felicidade, elevando os niveis de ansiedade das pessoas. Esse apetite por novidade faz com que os consumidores submetam-se aos ciclos da moda cada vez mais rápido.

Salcedo (2014) conclui que existem duas principais causas para criarmos um modelo que coloca em risco a continuidade de um sistema em sua origem saudável, como é a natureza, sendo elas: um problema de conceito e outro de comportamento. 0 primeiro consiste na dificuldade humana em perceber que a economia, a sociedade e o meio ambiente são sistemas interdependentes, porém separados, mas que precisam ser vistos de forma integrada, na qual o bem-estar econômico depende do bem-estar social que, por sua vez, depende do bem-estar do meio ambiente. Também que os dois últimos são fins em si mesmos e a economia é apenas um meio para garantir o bem-estar. 0 segundo problema tem origem no primeiro, partindo do conceito equivocado de que a natureza está a serviço do homem, que direcionou as práticas sociais para um consumo de recursos naturais em um ritmo mais acelerado do que a capacidade da natureza de repô-los. Por consequência, leva à produção de resíduos e poluição em tal velocidade que é impossível para a natureza absorvê-los.

Ao pensarmos um produto de moda, é possível evidenciar, só na indústria têxtil, uma série de impactos ambientais e sociais que contribuem cada vez mais rapidamente, à medida que a moda acelera, com a insustentabilidade de todo o sistema. São exemplos de impactos ambientais o uso intensivo de produtos químicos nos processos de cultivo e na extração de matéria-prima e fiação que degradam principalmente rios e mares; o uso intensivo de água, recurso não renovável, em várias fases do ciclo de vida do produto, desde as lavouras até as lavagens; as emissões de gases nas fases de produção, transporte, uso e manutenção; a produção de resíduos sólidos, além da própria roupa e de embalagens que em algum momento serão descartadas; o uso de 
recursos finitos, como o petróleo, na fabricação da matéria-prima; e a perda da biodiversidade em decorrência de monoculturas para a produção de fibras. Entre os impactos sociais estão as condições de trabalho que vão desde a insalubridade e a insegurança no setor até a exploração de mão de obra de diversas faixas etárias; 0 uso de tóxicos que ameaçam a saúde dos trabalhadores e de comunidades que se encontram no entorno de lavouras e fábricas; e a uniformização dos mercados sobrepondo, principalmente, a identidade cultural dos paises em desenvolvimento que recebem grande parte dos resíduos têxteis mundiais (SALCEDO, 2014).

Ao focar no design, encontramos no desenvolvimento de projetos de produtos que sejam ambientalmente corretos, economicamente viáveis e socialmente justos, manifestando um rumo para a sustentabilidade.

Produzir sem destruir e conceber um objeto do cotidiano, do mais elementar ao mais sutil, tornando seu uso durável e seu fim assimilável por outros processos de vida, deve ser a finalidade de uma reflexão global que considera a complexidade dessa relação. Ela transita por esse vínculo que une o homem ao objeto, desde a simples sobrevivência até a recordação de seus menores desejos. Nenhuma sabedoria pode ser esquecida nessa empreitada de imaginação e necessidade. (KAZAZIAN, 2005, p. 28)

0 processo de transição em direção à sustentabilidade não consiste em projetar estilos de vida sustentáveis, mas sim em propor oportunidades que tornem tais estilos praticáveis (MANZINI; VEZZOLI, 2008). 0 designer, nesse sentido, passa a ser intérprete de demandas ambientais e sociais mediando, valorizando e facilitando a emersão de novas maneiras de sociabilização, estilos de vida e identidade. Seu papel cresce e sua responsabilidade passa de soluções técnicas para soluções atrativas, uma vez que, para que haja uma inovação radicalmente sustentável, é preciso que as pessoas assim desejem. Aqui, ouso dizer: é necessário que a sustentabilidade entre na moda e, mais, que as pessoas assimilem e se empoderem em um movimento bottom-up.

Diversos fatores psicológicos ajudam a explicar por que os indivíduos são motivados a estar na moda, entre eles, a conformidade social, a procura pela vaidade, a criatividade pessoal e a atração sexual. Em geral, os consumidores têm necessidade de serem únicos, quase como uma autoafirmação, mas não tão diferentes a ponto de perderem sua identidade social.

0 comportamento do consumidor pode ser explicado pela necessidade de expressar significados mediante a posse de produtos que comunicam à sociedade como o individuo se percebe enquanto integrante de grupos sociais e também pela necessidade de ansiar por novidades constantes que remetem à ideia de estar inserido na moda, logo, os atributos simbólicos são dependentes do contexto social.

Canclini (2010) sintetiza os estudos que apontam o consumo como um lugar de diferenciação e distinção entre as classes e os grupos chamando atenção para os aspectos simbólicos e estéticos da racionalidade consumidora. 
Neles, a lógica que rege a apropriação dos bens como objetos de distinção não é a da satisfação de necessidades, mas sim a da escassez desses bens e da impossibilidade de que os outros os possuam. Sob este último viés, que propõe questões de distinção, estão pautados não somente a riqueza financeira e 0 acúmulo de bens, mas também o sacrifício de não possuir ou consumir pautando-se em critérios de maneira mais consciente.

Progressivamente, o consumidor deixa de se encantar pela publicidade e passa a ler os rótulos - esse comportamento é melhor exposto no consumo de cosméticos: para atender esse novo perfil, a indústria cosmética passou a estampar os princípios ativos das composições como diferenciais. Essa desconfiança também está presente na moda e é um dos fatores que aproximam as pessoas dos blogs de moda em detrimento das publicidades tradicionais. Tal como os consumidores de cosméticos, os de vestuário de moda passam a se interessar e a se informar sobre os produtos, expressando sua opinião, testando e validando o que é consumido.

Uma vez que o consumidor adquire comportamento de consumidor consciente torna-se um propagador de um novo discurso. Desse modo, uma vez que o vestuário de moda passa a agregar caracteristicas sustentáveis, o usuário poderá comunicar que é um sujeito consciente, sensivel à mudança de paradigma e que se preocupa com as futuras gerações e a preservação de todo o ecossistema do planeta.

0 fator condicionante para esse tipo de comportamento é o estágio do envolvimento pessoal, subjacente às motivações na forma de necessidades, valores e autoconceito alarmados a partir do momento que o bem (produto ou serviço) é identificado como instrumento de significado para as suas necessidades, metas e os seus valores.

Já que as mudanças na moda dependem da cultura estabelecida e dos ideais sociais que a compõem, comumente incorre-se no entendimento da incompatibilidade da moda no contexto do desenvolvimento sustentável. Entretanto, essa também pode ser uma saída, pois, sob a aparentemente tranquila superfície da cultura, estão intensas correntes psicológicas das quais a moda rapidamente capta a direção. Então, se há uma sociedade democrática na qual existem diversas iniciativas e movimentos para estabelecer o desenvolvimento sustentável, a moda rapidamente irá incorporá-Ios (SCHULTE; LOPES, 2008).

A partir das análises feitas evidencia-se como as digital influencers organizam-se em torno de produtos, construindo sua imagem, e, por meio do uso, estimulam o ciclo da moda. Esse processo permeia o público e o privado como um ofício no qual elas se mostram e, assim, falam de si por meio de seus artefatos e da relação que estabelecem com eles.

A pesquisa evidenciou que as ações de estratégia do design para otimizar a vida de produtos de moda são percebidas pelas digital influencers a partir de uma noção de sustentabilidade, contudo não são totalmente consideradas durante o uso devido à valorização dos aspectos simbólicos e culturais, especialmente aqueles relacionados à novidade. 
Os artefatos projetados para serem otimizados como uma estratégia para o consumo consciente, ao agregarem e considerarem os aspectos simbólicos e culturais, não só ensinam o consumidor a utilizá-los como também estimulam o seu uso de maneira equivalente.

Assim, as digital influencers aprendem que um lenço pode ser uma blusa quando há essa possibilidade de uso. Elas percebem que não precisam comprar outras roupas se usam as que já possuem de maneiras diferentes, renovando-se. Indo além, elas se envolvem emocionalmente com suas roupas quando estas dialogam com o seu estilo e aprendem a usar um botão reserva em substituição a um perdido quando este encontra-se disponivel com o produto. Por fim, elas apreendem a complexidade de execução de um produto artesanal quando o processo produtivo é informado.

Ao entender que é pelo uso que fazemos das coisas - como as representamos - que lhes damos significado, construímos em nós um significado e nos reinventamos diariamente. Nossas escolhas diárias e rotineiras também reconstroem nossa relação com o consumo. Por isso, mais do que apresentar os resultados de uma pesquisa que gira em torno de uma temática tão oportuna para a moda e seu ensino, buscou-se fazer de tal relevância um motivo a mais para o compartilhamento de informações. Aqui, neste artigo, não obstante,

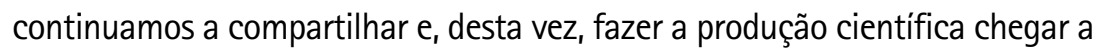
um maior número de pessoas.

\section{Como compartilhar?}

Ao iniciar o projeto Moda pelo avesso, a metodologia adotada surgiu como grande desafio. Para isso, buscou-se um momento de culminância com um formato atrativo a fim de promover a socialização de resultados acadêmicos para um público diversificado e com uma visão de senso comum arraigada sobre a moda.

Valemo-nos do que Ingold (2015) nos diz sobre o conhecimento por meio da prática com as pessoas envolvidas continuamente pela percepção háptica e na ação dentro de um campo de relações estabelecidas por meio da imersão. Assim, o projeto de extensão Moda pelo avesso culminou em evento com o mesmo nome realizado em dia único, 24/5/2017, no auditório do IFMA - campus Zé Doca.

Nesse mesmo dia, movimentavam a cidade grandes e aguardadas queimas de estoque e liquidações das maiores lojas da região que comercializam desde eletrodomésticos e móveis até tecidos e confecções. As promoções começavam às 6 horas e duravam até as 18 horas. Embora a escolha do dia fosse proposital, em uma cidade pequena nosso interesse não era ir de encontro aos comerciantes e consumidores locais, mas suscitar reflexões sobre consumo sustentável diante daquela realidade. Por isso, o evento só se iniciou a partir das 18 horas, quando as lojas já estavam com as portas fechadas.

0 evento aconteceu sob a coordenação da professora autora do projeto e com apoio de dois voluntários. Sua divulgação foi realizada por meio de 
cartazes, mídias sociais e imprensa local. 0 material gráfico utilizado, tanto nos cartazes como nos banners digitais em mídias sociais, foi desenvolvido pela coordenadora do evento e a assessoria de imprensa foi articulada pelo departamento de relações interinstitucionais do campus.

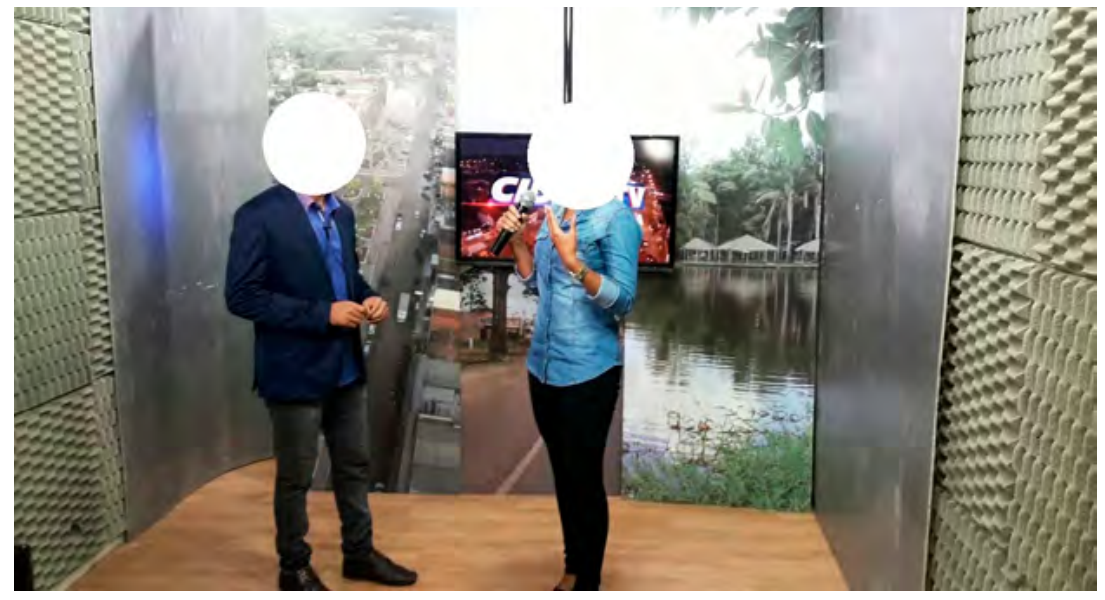

Figura 2 - Divulgação do evento em programa de televisão local.

Fonte: Arquivo pessoal (2017).

Durante a fase de divulgação, houve a oportunidade de esclarecer questões que rodeiam a moda carregadas de estereótipos. Nas entrevistas esclareceu-se, principalmente, que o público-alvo do evento não era exclusivamente feminino e que todos estavam convidados, tendo em vista que todos que consomem devem assumir a sua responsabilidade. Assim, 0 [ 23I ] público-alvo era a comunidade em geral, especialmente empresários, estudantes e interessados na área.

Foram previstas 50 pessoas e atendemos 117 participantes. 0 controle de presença foi realizado por meio de folha de frequência, constando campos para o preenchimento dos dados necessários para os encaminhamentos de certificação. A apresentação teve caráter expositivo, definido como uma palestra proferida pela própria autora da dissertação, com duração de 45 minutos e 15 minutos destinados às dúvidas e aos questionamentos. A explanação usou como recurso didático uma apresentação em Power Point projetada e abordou o tema pesquisado, a metodologia aplicada e a apresentação dos resultados.

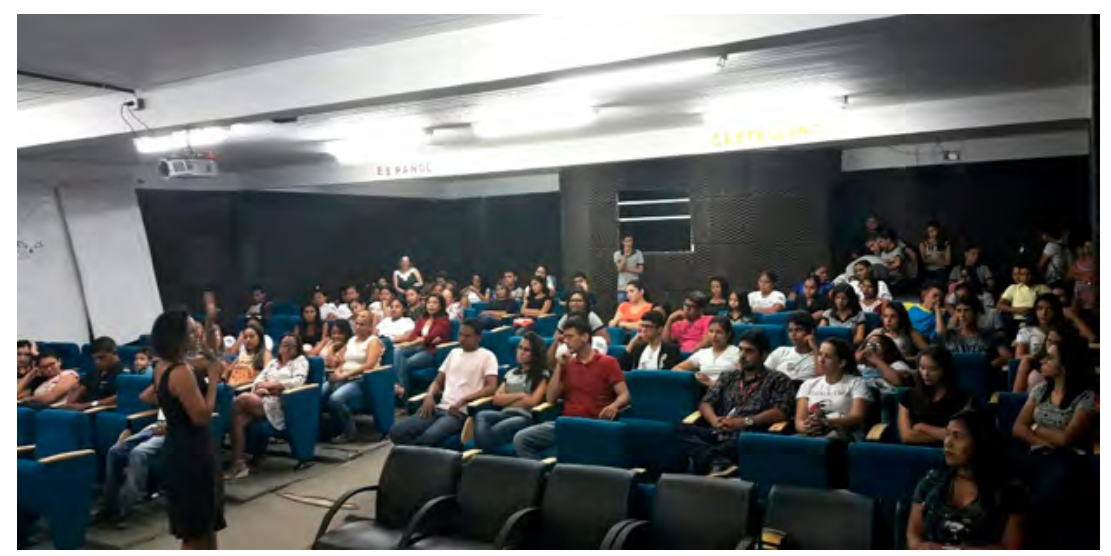

Figura 3 - Palestra no evento Moda pelo avesso. Fonte: Arquivo pessoal (2017). 
Foram temas de debates as ações de projetar a duração adequada (1), tais como os modelos de moda slowe fast; projetar a fidelidade (2) a partir de uso de peças básicas; facilitar a atualização e adaptabilidade (3) com o uso de produtos multifuncionais; facilitar a manutenção (4), questionando a leitura correta das etiquetas; facilitar o reparo (5) com o uso de botões e outros aviamentos reservas; e intensificar o uso (8) por meio do compartilhamento de peças de vestuário.

Após a realização da palestra e findado o momento de debates e perguntas, realizou-se uma avaliação do evento, identificando outros temas de interesse da comunidade que podem suscitar novos projetos de extensão.

Considerando Ingold (2012), entendemos que a informação abre caminho para o conhecimento que marca os sujeitos pela experiência e cresce dentro de cada um. Logo, aprender é uma prática que se relaciona à criatividade e à improvisação, exigindo também um engajamento sensorial. Por meio da possivel identificação de práticas dos sujeitos da pesquisa, o público participante do evento - estudantes, empresários, educadores e interessados no tema moda - poderá reproduzir novas posturas diante dos produtos consumidos, tornando-se sujeitos ativos na solução de problemas que os distanciam da sustentabilidade na cidade de Zé Doca (MA).

\section{Considerações finais}

A pesquisa de mestrado trouxe à tona que mesmo com a democratização do acesso às informações, facilitada pela rede mundial de computadores, a comunicação ainda é um entrave para o consumo sustentável, por isso, um de seus desdobramentos é a necessidade de ampliar o acesso às informações, fazendo com que o consumidor se torne cada vez mais exigente e questionador do sistema da moda como um todo.

Logo, por meio do evento Moda pelo avesso, a instituição escolar que tem como pilares o ensino, a pesquisa e a extensão também cumpre com o seu papel social quando expande para a comunidade de modo geral informações sobre todo o ciclo de vida de um produto, que, muitas vezes, é estrategicamente velado, e estimula reflexões sobre nossas práticas cotidianas de consumo.

Na ocasião do evento foi discutida a postura institucional das empresas, a ética e a transparência com que se relacionam com os consumidores. Nesse sentido, a origem dos materiais bem como as condições de trabalho dentro da cadeia produtiva têxtil e de confecção são consideradas informações importantes a serem socializadas e nem sempre são.

Percebemos que a falta de informação também garante a construção do mito de que o produto sustentável é caro e feio. Tais características estão diretamente associadas a um posicionamento do designer dentro da cadeia produtiva. 0 custo final de uma peça é resultado de uma compilação de escolhas e a transparência também tende a justificar e tornar facilitada a aceitação do preço. Quanto à questão estética, aqui cabe uma reflexão comparativa uma 
vez que os consumidores de produtos de moda estão acostumados com a estética habitual de produtos não sustentáveis.

Embora seja inerente à moda a aproximação com o novo, esta precisa ser estrategicamente ponderada de modo a modelar o gosto dos consumidores para outra estética, inclusive a mais natural. A simplificação dos produtos, enquadrando-os na categoria de básicos, deixando a cargo do usuário as composições inovadoras, é uma boa estratégia. Ela foi reconhecida tanto pelas digital influencers na dissertação quanto pelos participantes do evento.

Foram apontadas pelas digital influencers como práticas de consumo responsável a aquisição e a venda via bazar e brechós. Tais ações exemplificam uma abordagem bottom-up, precisando ser consideradas pelo design, aprimoradas e devolvidas ao consumidor, incorporando a prática por meio da emoção. Especialmente essa prática chamou bastante atenção dos participantes do evento e eles sinalizaram interesse de, após a sua realização, articularem-se para realizar compartilhamento de peças de vestuário.

0 compartilhamento de produtos extrapola a materialidade, pois junto com eles vêm histórias que podem ser igualmente compartilhadas, no sentido de envolver tanto aquele que desapega do produto quanto aquele que 0 adquire. Assim, surgem demandas para novos empreendimentos, tais como a implantação de um guarda-roupa coletivo na cidade de Zé Doca (MA), como um PSS, garantindo uma possibilidade para aqueles que desejam desfazer-se de seus produtos e, ao mesmo tempo, privilegiam a intensificação do uso.

Nesse sentido, outras pesquisas tornam-se oportunas visando identificar a continuidade e 0 impacto de tais ações fomentadas pelo projeto aqui relatado. Afinal, é pertinente acompanhar o comportamento do consumidor no intuito de ter nele não só um termômetro para a indústria, mas, principalmente, a compreensão dos fatos sociais.

Diante do exposto, avalia-se bem-sucedida a socialização da produção científica como uma exigência institucional que ganha projeção, suscita reflexões e novas práticas. De fato, vemos o conhecimento ultrapassar os limites da instituição de ensino e reverberarem na sociedade.

Recebido em: 21-01-2018

Aprovado em: 13-03-2018 


\section{REFERÊNCIAS}

BAUMAN, Zygmunt, Vida para consumo. Rio de Janeiro: Zahar, 2008.

CANCLINI, N. G. Consumidores e cidadãos. 8. ed. Rio de Janeiro: Ed. UFRJ, 2010.

CARVALHAL, André. Moda com propósito: manifesto pela grande virada. 1. ed. São Paulo: Paralela, 2016.

IBGE. Censo demográfico. 2010. Disponivel em: <https://cidades.ibge.gov.br/v4/brasil/ma/ze-doca/ panorama>. Acesso em: 6 jun. 2017.

INGOLD, Tim. 2012. Trazendo as coisas de volta à vida: emaranhados criativos num mundo de materiais. In: Horizontes Antropológicos, 18, n. 37, pp. 25-44. Porto Alegre.

2015. Estar vivo: ensaios sobre movimento, conhecimento e descrição. São Paulo: Vozes.

ERNER, Guillaume. Sociologia das tendências. 1. ed. São Paulo: Gustavo Gili, 2015.

GODART, Frédéric. Sociologia da moda. São Paulo: Ed. Senac São Paulo, 2010.

KAZAZIAN, Thierry. Haverá a idade das coisas leves: design e desenvolvimento sustentável. São Paulo: Senac, 2005.

LIPOVETSKY, Gilles. A sociedade da decepção. Barueri: Manole, 2007.

MANZINI, Ezio; VEZZOLI, Carlo. 0 desenvolvimento de produtos sustentáveis: os requisitos ambientais dos produtos industriais. São Paulo: Editora da Universidade de São Paulo, 2008.

PERPÉTUO, Nayara Chaves Ferreira. No cabide: a percepção das digital influencers sobre a estratégia de design para otimização de produtos. São Luis, 2017. 150 f. Dissertação (Mestrado) - Programa de PósGraduação em Design, Universidade Federal do Maranhão.

SALCEDO, Elena. Moda ética para um futuro sustentável. São Paulo: GGmoda, 2014.

SCHULTE, Neide Köhler; LOPES, Luciana. Sustentabilidade ambiental: um desafio para a moda. In: ModaPalavra e-periódico, ano 1, n. 2, pp. 30-42, ago./dez. 2008. 